\title{
The Effect of Obesity and Overweight on Pulmonary Function in School-Aged Children
}

\author{
Nurshan Mohamed Hamzah, Ahmed Chreitah, Maamoun Hakim \\ Faculty of Medicine, Department of Pediatrics, Tishreen University, Lattakia, Syria \\ Email address: \\ nurshan.m.hamzah@tishreen.edu.sy (N. M. Hamzah), ahmed.chreitah@tishreen.edu.sy (A. Chreitah), \\ mamounhakim5@yahoo.com (M. Hakim)
}

\section{To cite this article:}

Nurshan Mohamed Hamzah, Ahmed Chreitah, Maamoun Hakim. The Effect of Obesity and Overweight on Pulmonary Function in SchoolAged Children. American Journal of Pediatrics. Vol. 7, No. 3, 2021, pp. 154-158. doi: 10.11648/j.ajp.20210703.22

Received: June 27, 2021; Accepted: July 28, 2021; Published: August 11, 2021

\begin{abstract}
Background: Obesity has an increasing prevalence worldwide in both industrial and developing countries. It also leads to serious complications among most body systems including the respiratory system; which has not been well studied and proven in Arab countries. Objective: To evaluate the association between obesity degrees, and pulmonary function parameters. Methods: Non-asthmatic children aged 5 to 14 years old were enrolled in this study. We obtained height and weight for each child then we calculated body mass index. We performed pulmonary function tests using spirometer. Results: This study included a total of 99 children (51 boys, 49 girls), the mean age was 10.5 years. Spirometric parameters such as Forced Vital Capacity (FVC) was higher in children with overweight and obesity. While Forced Expiratory Volume during the first second (FEV1) in addition to FEV1 to FVC Ratio were lower in children with overweight and obesity. There also was a negative linear correlation between Body Mass Index in percentiles and FEV1, FEV1/FVC Ratio, which reflects an airway obstruction inappropriate with lung volumes. Conclusion: we recommend conducting the measurement of pulmonary function via spirometer within the investigations of children with overweight and obesity to detect pathological changes as early as possible.
\end{abstract}

Keywords: Obesity, Overweight, BMI, FVC, FEV, FEV1/FVC Ratio

\section{Background}

Obesity is a challenging public health issue affecting both high and low-income countries [1]. According to the Global Nutrition, there was 330 million obese and overweight child aged 5-19 years old in 2016 [2]. In Arab countries, The prevalence of obesity among adolescents ranged from 5.7\% in Tunisia to $24.8 \%$ in Kuwait [3]. Positive Energy Balance in addition to Genetic predispositions are the principle reasons for childhood obesity [4]. Overweight in children is defined as BMI at or above the 85th percentile for age and sex, while obesity is defined as BMI for age and sex at or above $95^{\text {th }}$ percentile [5]. Obesity increases risk for Metabolic Syndrome [6], Coronary Artery Disease (CAD) [7], Diabetes Mellitus Type 2 [8], many types of malignancy [9] and early death in adulthood [10], It also causes respiratory diseases such as Sleep Apnea [11] and about a quarter of all Asthma cases in children [12]. Forno found in his review on pulmonary function test results in adults with obesity that there was an inverse correlation between BMI and lung volumes (FEV1, FVC) with normal FEV1/FVC ratio which reflects a restrictive ventilatory deficit [13]. While in children, the most common observed abnormality in spirometric parameters was the inverse association between BMI and FEV1/FVC ratio which reflect an obstructive ventilatory deficit or airway dysanapsis [14]. The cardiovascular complications of obesity have been known and proven by researchers [15] while studies on respiratory complications are still limited with inconsistent results [16] as well as these complications tend to be silent and can cause -without treatment- irreversible pulmonary hypertention and heart failure [17], this confirms the importance of investigating it early in childhood period. And that is what our study aims to.

\section{Methods and Materials}

One hundred-fourteen non-asthmatic children aged 5 to 14 
years old who were admitted to our pediatric outpatient department from May 2020 to May 2021 were enrolled in this study. Fifteen patients were excluded (12 had respiratory infection, 1 had scoliosis, 2 were unable to do lung function due to mental retardation). We obtained consent forms from children and their parents. Height was measured to the nearest $0.5 \mathrm{~cm}$ on a standard height board without shoes. Weight was measured to the nearest $0.1 \mathrm{~kg}$ without heavy clothes.

BMI was calculated by dividing the weight (kilograms) by the square of the height (meters).

Pulmonary function tests were recorded in the sitting position, using Vitagraph ALPHA, model 6000, spirometer according to the recommendations of the ATS-ERS 2019 [18]. The following data were obtained by Forced Expiratory maneuver: FEV1, FVC, FEV1/FVC ratio. During the measurement, volume and flow curves were closely monitored to detect artifacts and confirm enough efforts.

Statistical Analysis
This study was a cross-sectional Analytic study. Quantitative Variables were expressed as Means and standard deviations. Qualitative variables were expressed as frequencies and percentiles. One-way ANOVA Test was used to assess the differences between BMI related groups of children and spirometric indicides. Chi-square Test was used to assess the statistical significance of the difference between categorical variables. Pearson Correlations were calculated to analyse the association between BMI percentiles and pulmonary function parameters FEV1, FVC, FEV1/FVC ratio. SPSS, version 20 was used for Statistical analysis. Statistical significant was considered for $\mathrm{P}$ values less than 0.05 .

\section{Results}

A total of 99 children (51 boys, 51.5\%) were enrolled in this study with a mean age of 10.5 years. table 1 .

Table 1. Shows the distribution of 99 children according to age groups, the largest proportion $36.4 \%$ was in the 12 to 14 year old group.

\begin{tabular}{lll}
\hline Age groups (years) & number & Percent\% \\
\hline$[6-8]$ & 17 & $17.2 \%$ \\
{$[8-10]$} & 23 & $23.2 \%$ \\
{$[10-12]$} & 23 & $23.2 \%$ \\
{$[12-14]$} & 36 & $36.4 \%$ \\
\hline
\end{tabular}

They were divided into 4 groups: 22 Normal weight (BMI $>5 \%)(22.2 \%), 25$ overweight $(\mathrm{BMI} \geq 85 \%)(25.3 \%), 26$ obese $(\mathrm{BMI} \geq 95 \%)(26.3 \%)$ and 26 morbidly obese (BMI $\geq 99 \%)(26.3 \%)$. table 2 .

Table 2. Shows the distribution of 99 children according to BMI percentiles, the largest proportion $52.5 \%$ was in the obese groups.

\begin{tabular}{lll}
\hline BMI\% & number & Percent\% \\
\hline Normal weight & 22 & $22.22 \%$ \\
overweight & 25 & $25.24 \%$ \\
obese & 26 & $26.26 \%$ \\
Morbidly obese & 26 & $26.26 \%$ \\
\hline
\end{tabular}

There was a high prevalence of exposure to passive smoking in home environment in the study population: 17 patient of normal weight group $(77.3 \%)$ and 63 patients of overweight and obesity group $(81.8 \%)$ with no significant difference ( $P$ value $=0.2$ ). There was also no significant difference in age $(p=0.4)$ or sex $(p=0.7)$ between these two groups of children. The spirometric parameters of the four BMI-related groups of children are shown in table 3. BMI was statistically significant with the $\%$ expected of FVC $(\mathrm{P}=0.0001)$, FEV1 $(\mathrm{P}=0.0001)$ values and the FEV1/FVC ratio $(\mathrm{P}=0.0001)$.

Table 3. The differences in mean values of pulmonary function parameters between children with normal weight group and children with overweight and obesity group, FVC was higher in the second group while FEV1 and FEV1/FVC ratio were lower in it.

\begin{tabular}{llll}
\hline PFT parameters & Normal weight $\mathbf{n = 2 2}$ & Overweight and Obesity n=77 & P-value \\
\hline FVC\% & $91.18 \pm 3.1$ & $78.88 \pm 7.05$ & 0.01 \\
FEV1\% & $90.04 \pm 4.8$ & $100.58 \pm 10.5$ & 0.04 \\
FEV1/FVC\% & $91.77 \pm 2.9$ & $77.05 \pm 7.6$ & 0.03 \\
\hline
\end{tabular}




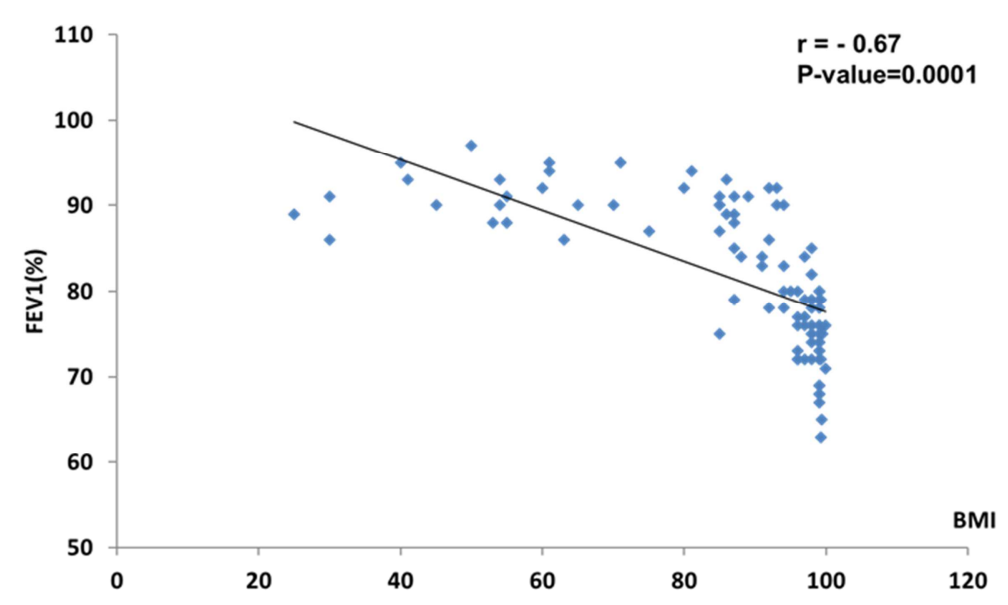

Figure 1. The negative linear correlation between BMI\% and FEV1\%.

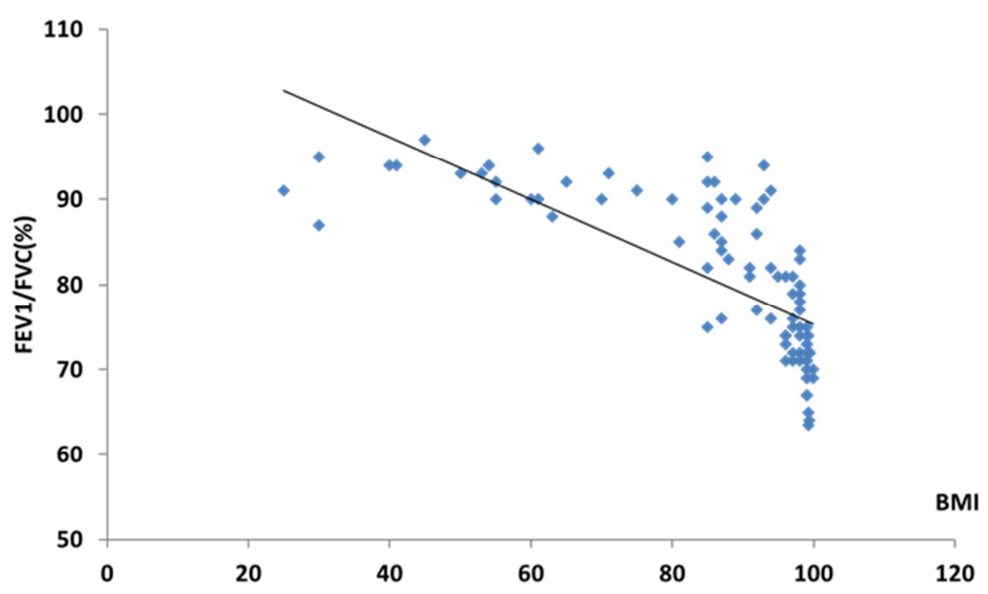

Figure 2. The negative linear correlation between BMI\% and FEVI/FVC\%.

By correlations we found a statisfically significant negative linear correlation between $\mathrm{BMI} \%$ and $\mathrm{FEV} 1$ figure 1, also between BMI\% and FEV1/FVC Ratio figure 2.

\section{Discussion}

In this study our results suggest that pulmonary function in children with overweight and obesity defined by BMI percentiles characterized by reduction in FEV1, FEV1/FVC ratio and elevation in FVC. The reduction in FEV1 and FEV1/FVC ratio reflects contraction in the airways similar to asthmatic children, as known obesity is associated with chronic low-grade systemic inflammatory condition [19] due to Leptin, an adiponectin secured from white adipose tissue, which increases the pro-inflammatory cytokines such as TNF-a and IL-6 which cause bronchial hypersensitivity [20], Leptin also enhances the chemo-attraction of Eosinophills resulting in allergic reaction in the airways [21]. Leptin also responsible for remodeling of the airways mediated by Vascular Endothelial Growth Factor (VEGF), leading to increased airway resistance [22]. High FVC levels reflects lung volumes' growth compatible with BMI, but not with airways diameters. [23]

Davidson was found in his retrospective study of children aged 6-17 years old a positive linear correlation between BMI z-score and percent predicted $\mathrm{FVC}$, and a negative linear correlation with FEV1/FVC ratio as we found, for both males and females, but unlike us he didn't find a significant association with FEV1 [24]. The negative linear correlation between BMI and FEV1 in our study may be due to the synergistic effect of passive smoking exposure to the pulmonary function. Cibella investigated the effect of BMI on pulmonary function in healthy children aged 10-17 years and found that FVC (as percentile predicted) was higher in children with overweight and obesity $(\mathrm{P}=0.0003)$ while FEV1, and FEV1/FVC ratio was lower in them $(\mathrm{P}<0.0001)$ which reflect a reduction in airway size inappropriate with the growth of lung volumes [25]. Akin found a statistically significant negative correlation among FEV1, FEV1/FVC and BMI in children aged 5-15 years [26]. The inverse association between BMI and FEV1/FVC ratio contributes to a higher incidence of Asthma in obese males and females [27]. Spathopoulos found that obesity in children accompanised with reduced FVC with a normal FEV1/FVC ratio [28]. The children ages in his study ranged between 7 and 11 years old while $59.6 \%$ of our study population were more than 10 years old, which may suggest an effect of puberty on pulmonary function due to increased muscle mass 
in males and peripheral distribution of fat in females. Webb didn't find a direct correlation between BMI and spirometric values, her study included only 35 patients who had obesity without comparison with normal weight group [29].

This study has some limitations, it didn't include the effect of fat distribution on Pulmonary function tests, we also coudn't exclude children exposed to passive smoking due to its wide prevalence in our society.

\section{Conclusion}

In this study, we found that obesity with all its degrees leads to pathological changes in lung function measured by spirometer, which does not up to clinically explicit harm in the childhood period.

A statistically significant linear relationship was found between obesity scores and changes in lung function values, as the higher the BMI values, the higher the FVC values, while the FEV1 and FEV1/FVC values decrease, similar to the changes seen in the context of asthma. However, this is a cross-sectional study, more longitudinal studies are needed to investigate how reduction of weight can affect pulmonary function in children and adolescents. Further studies about the effect of passive smoking exposure on respiratory system are needed too.

\section{Competing of Interests}

The authors have no affiliation with any organization with a direct or indirect financial interest in the subject matter discussed in the manuscript.

\section{Ethical Considerations}

All the children freely accepted to be part of the study and the permission from their parents was taken.

\section{Author Contributions}

All authors have participated in (a) conception and design, or analysis and interpretation of the data; (b) drafting the article or revising it critically for important intellectual content; and (c) approval of the final version. Literature review was done by Dr. Nurshan Mohamed Hamzah.

\section{Acknowledgements}

We wish to thank Eng. Abdulrahman Airout for his support, all doctors in Tishreen University Hospital, Department of Pediatrics, especially Dr. Douaa Kharbotly, Miss Alissar Hejazia for the technical help, and all children and their parents.

\section{References}

[1] World Health Organization. Childhood overweight and obesity [Internet] Geneva: WHO; 2016.
[2] Global Nutrition Report Shining a Light to Spur Action on Nutrition 2018. World Health Organization. Available online: https://www.who.int/nutrition/globalnutritionreport/2018 Glo bal_Nutrition_Report.pdf (accessed on 30 December 2020).

[3] Musaiger, Abdulrahman O., et al. "Prevalence of overweight and obesity among adolescents in eight Arab countries: comparison between two international standards (ARABEAT2)." Nutricion hospitalaria 33.5 (2016): 1062-1065.

[4] Kumar, S., \& Kelly, A. S. (2017, February). Review of childhood obesity: from epidemiology, etiology, and comorbidities to clinical assessment and treatment. In Mayo Clinic Proceedings (Vol. 92, No. 2, pp. 251-265). Elsevier.

[5] Cole, T. J., Bellizzi, M. C., Flegal, K. M., \& Dietz, W. H. (2000). Establishing a standard definition for child overweight and obesity worldwide: international survey. Bmj, 320 (7244), 1240 .

[6] Gepstein, V., \& Weiss, R. (2019). Obesity as the main risk factor for metabolic syndrome in children. Frontiers in endocrinology, 10, 568 .

[7] Attard SM, Herring AH, Howard AG, Gordon-Larsen P. Longitudinal trajectories of BMI and cardiovascular disease risk: the national longitudinal study of adolescent health. Obesity (Silver Spring).

[8] Geng, T., Smith, C. E., Li, C., \& Huang, T. (2018). Childhood BMI and adult type 2 diabetes, coronary artery diseases, chronic kidney disease, and cardiometabolic traits: a Mendelian randomization analysis. Diabetes care, 41 (5), 1089-1096.

[9] Weihrauch-Blüher, S., Schwarz, P., \& Klusmann, J. H. (2019). Childhood obesity: increased risk for cardiometabolic disease and cancer in adulthood. Metabolism, 92, 147-152.

[10] Lindberg, L., Danielsson, P., Persson, M., Marcus, C., \& Hagman, E. (2020). Association of childhood obesity with risk of early all-cause and cause-specific mortality: A Swedish prospective cohort study. PLoS medicine, 17 (3), e1003078.

[11] Fiorino, Elizabeth K., and Lee J. Brooks. "Obesity and respiratory diseases in childhood." Clinics in chest medicine 30.3 (2009): 601-608.

[12] Lang, Jason E., et al. "Being overweight or obese and the development of asthma." Pediatrics 142.6 (2018).

[13] Forno, E., Han, Y. Y., Mullen, J., \& Celedón, J. C. (2018). Overweight, obesity, and lung function in children and adults - a meta-analysis. The Journal of Allergy and Clinical Immunology: In Practice, 6 (2), 570-581.

[14] di Palmo, Emanuela, et al. "Childhood Obesity and Respiratory Diseases: Which Link?." Children 8.3 (2021): 177.

[15] Csige I, Ujvárosy D, Szabó Z, et al. The Impact of Obesity on the Cardiovascular System. J Diabetes Res. 2018; 2018: 3407306. Published 2018 Nov 4. doi: $10.1155 / 2018 / 3407306$.

[16] Torun, Emel, et al. "The effect of obesity degree on childhood pulmonary function tests." Balkan medical journal 31.3 (2014): 235. Parameswaran K, Todd DC, Soth M. Altered respiratory physiology in obesity. Can Respir J 2006; 13: 203-210. 
[17] Ayinapudi, Karnika, et al. "Obesity and pulmonary hypertension." Current hypertension reports 20.12 (2018): 1-8.

[18] Miller, M. R., Hankinson, J. A. T. S., Brusasco, V., Burgos, F., Casaburi, R., Coates, A.,... \& Wanger, J. A. T. S. (2005). Standardisation of spirometry. European respiratory journal, $26(2), 319-338$.

[19] Gomez-Llorente, M., Romero, R., Chueca, N., MartinezCañavate, A., \& Gomez-Llorente, C. (2017). Obesity and asthma: a missing link. International journal of molecular sciences, 18 (7), 1490.

[20] Paz-Filho, Gilberto, et al. "Leptin: molecular mechanisms, systemic pro-inflammatory effects, and clinical implications." Arquivos Brasileiros de Endocrinologia \& Metabologia 56 (2012): 597-607.

[21] Grotta, M. B., Squebola-Cola, D. M., Toro, A. A. et al. Obesity increases eosinophil activity in asthmatic children and adolescents. BMC Pulm Med 13, 39 (2013).

[22] Shin, J. H., Kim, J. H., Lee, W. Y., \& Shim, J. Y. (2008). The expression of adiponectin receptors and the effects of adiponectin and leptin on airway smooth muscle cells. Yonsei medical journal, 49 (5), 804.

[23] Fretzayas, Andrew, et al. "Is obesity related to the lung function of non-asthmatic children?." World journal of clinical pediatrics 7.2 (2018): 67.
[24] Davidson, W. J., Mackenzie-Rife, K. A., Witmans, M. B., Montgomery, M. D., Ball, G. D., Egbogah, S., \& Eves, N. D. (2014). Obesity negatively impacts lung function in children and adolescents. Pediatric pulmonology, 49 (10), 1003-1010.

[25] Cibella, F., Bruno, A., Cuttitta, G., Bucchieri, S., Melis, M. R., De Cantis, S.,... \& Viegi, G. (2015). An elevated body mass index increases lung volume but reduces airflow in Italian schoolchildren. PLoS One, 10 (5), e 0127154.

[26] Akın, O., Arslan, M., Haymana, C., Karabulut, E., Hacihamdioglu, B., \& Yavuz, S. T. (2017). Association of neck circumference and pulmonary function in children. Annals of Allergy, Asthma \& Immunology, 119 (1), 27-30.

[27] Robinson PD. Obesity and its impact on the respiratory system. Paediatr Respir Rev. 2014; 15 (3): 219-26.

[28] Spathopoulos, D., Paraskakis, E., Trypsianis, G., Tsalkidis, A., Arvanitidou, V., Emporiadou, M.,... \& Chatzimichael, A. (2009). The effect of obesity on pulmonary lung function of school aged children in Greece. Pediatric pulmonology, 44 (3), 273-280.

[29] Webb A, Siddaiah R, Pirzada M, Islam S, Halaby C, et al. Pulmonary Function Test Abnormalities in Obese NonAsthmatic Children and Adolescents. Sci J Pulm Respir Med. 2017; 1 (1): 019-023. 